AperTO - Archivio Istituzionale Open Access dell'Università di Torino

Reversed Brayton cycle for food freezing at very low temperatures: Energy performance and optimisation

This is a pre print version of the following article:

Original Citation:

Availability:

This version is available http://hdl.handle.net/2318/1645852

since 2021-08-12T09:34:45Z

Published version:

DOI:10.1016/j.jijrefrig.2017.05.022

Terms of use:

Open Access

Anyone can freely access the full text of works made available as "Open Access". Works made available under a Creative Commons license can be used according to the terms and conditions of said license. Use of all other works requires consent of the right holder (author or publisher) if not exempted from copyright protection by the applicable law. 


\section{(3) \\ UNIVERSITÀ DEGLI STUDI DI TORINO}

This is an author version of the contribution published on:

International Journal of Refrigeration, volume 81, 2017, doi.org/10.1016/j.ijrefrig.2017.05.022

A. Biglia, L. Comba, E. Fabrizio, P. Gay, A. Mannini, A. Mussinatto, D. Ricauda Aimonino

Volume 81, Elsevier, 2017, pag. 82 - 95

The definitive version is available at:

http://www.sciencedirect.com/science/article/pii/S014070071730213X 


\title{
Reversed Brayton cycle for food freezing at very low temperatures: Energy performance and optimisation
}

\author{
Abstract \\ Freezing is a valuable method to increase food shelf life and to ensure high quality standards during long- \\ term storage. Additional benefits to frozen food quality can be achieved by freezing at very low \\ temperatures $\left(«-50^{\circ} \mathrm{C}\right)$ : small ice crystals formation during fast freezing reduces food cell wall rupture, \\ preventing water and texture loss during thawing. \\ This paper presents the design of an innovative food freezing system operating at very low temperatures, \\ based on a modified reversed Brayton cycle ( $\mathrm{rB}$ cycle). The plant is composed of two interconnected sub- \\ systems: a primary thermodynamic closed loop, operated by an $\mathrm{rB}$ cycle, and a secondary airflow loop \\ which is devoted to food freezing by batch process. Relevant features of the designed rB cycle rely on the \\ adopted environmentally safe working fluid, the optimised thermodynamics working conditions and the \\ innovative cycle layout. \\ A modelling framework for the system was developed to identify and design efficient operative settings for \\ the plant components (turbo-machineries, heat exchangers, etc.) and to assess, via sensitivity analysis, the \\ influence of the main design parameters on the global energy performance. The proposed system \\ configuration, designed to maximise the Coefficient of Performance (CoP) value of the plant, was \\ determined by means of nonlinear multivariable optimisation. In addition, the energy performance of the \\ system can be increased by recovering waste heat available from the rB cycle.
}

Keywords: Food industry; Food freezing; Reversed Brayton cycle; Low temperatures; Energy performance; Optimisation

\section{Introduction}

Freezing is a valuable method to increase food shelf life, to preserve organoleptic and nutritional food properties, and to ensure high quality standards during long-term storage (Soyer et al., 2010). Contrary to other methods of food storage, such as drying (Tian et al., 2016), vacuum packaging (Li et al., 2014), salting (Lerfall et al., 2016), and smoking (Ledesma et al., 2016), freezing technology can be applied to almost any kind of food category.

In the freezing process, a cooling fluid (medium) removes sensible and latent heat from the food by convection through its surface while thermal conduction occurs at its interior (Castro-Giráldez et al., 2014). Usually, cold air is used as the medium in food industry freezing systems since it is not expensive and corrosive to plant components, it is environmentally friendly and does not contaminate foods (James and James, 2002): these systems are known as air blast freezers (Dempsey and Bansal, 2012). There are two categories of air blast freezers: batch freezers and continuous freezers. In batch freezing, the food is loaded into an insulated closed room and the process runs until the product is completely frozen. After that, the freezing room compartment is unloaded and the process can be run for other unfrozen food lots (batch process). Inside the room, cold air circulation is forced by fans during the freezing process. This kind of system is usually adopted to freeze medium to large sized products, such as meat, fish, bread, and even packaged foods. In continuous freezing, food products, usually arranged in a single layer, are moved through a freezing tunnel by a conveyor belt. This is a suitable process for freezing small foods such as legumes, prawns, slices of vegetables, etc. Since the food flow is continuous, air deflectors and/or movable 
shutters, properly placed at the inlet and outlet of the tunnel, have to be adopted in order to limit warm air infiltrations. Conveyor speed and tunnel length depend on the freezing time required by the kind of food to be processed.

Freezing time is a relevant parameter as it deeply affects the quality of the final product (Kim et al., 2015). Quick-freezing is preferred because water contained in the food is turned into minute ice crystals (Kaale et al., 2011). If the freezing process is too slow, the ice crystals tend to agglomerate and to grow in size, causing mechanical damage to food cell membranes. This unfavourable phenomenon results in texture and food nutrients being lost after thawing. Freezing time mainly depends on the following factors (ASHRAE, 2010; Huan et al., 2003; Perussello et al., 2011): (1) the chemical composition and shape of the food; (2) the initial and final temperatures of the food and (3) the temperature and velocity of the medium.

A food core temperature of about $-18^{\circ} \mathrm{C}$, which is recommended for frozen products, has to be reached in the shortest possible time. A reduction of the freezing time can be achieved by modifying medium temperature and/or velocity (Biglia et al., 2016), properties that deeply influence heat transfer between the product and the medium itself.

In the food industry, air blast systems typically adopt cold air, with temperatures ranging between - 20 and $40{ }^{\circ} \mathrm{C}$ and velocities from 1 to $6 \mathrm{~m} \cdot \mathrm{s}-1$. Vapour compression chillers are normally used to reduce air temperature until the desired design value. The Coefficient of Performance (CoP) of these systems depends on the temperature lift between the evaporator and the condenser of the chiller. Considering that the standard working temperature of a chiller for food freezing is usually within the range $[-50,-30]{ }^{\circ} \mathrm{C}$ in the evaporator and $[20,40]^{\circ} \mathrm{C}$ in the condenser, the resulting temperature lift leads to a high-pressure ratio in the compressor, which can barely be obtained with a single compression stage. A valuable solution consists in performing the compression in two different stages (Llopis et al., 2015). Even if this technical feature allows the system's efficiency to be increased, it is very difficult to obtain high CoP values. Alternatively, cascade refrigeration systems (Dopazo and Fernández-Seara, 2012), which use two different refrigeration circuits interconnected with a heat exchanger, can be adopted to reach low evaporator temperatures. Their installation and maintenance is, thus, more complex (Foster et al., 2011) than the one required for a single stage chiller. For these reasons, producing air significantly colder than $-30^{\circ} \mathrm{C}$ by using vapour compression chillers is complex and expensive.

Another possibility to enhance heat transfer, in order to bypass the difficulty of lowering the medium temperature, is to increase air velocity. Two different air blast freezer technologies, with the air at velocities higher than $20 \mathrm{~m} \cdot \mathrm{s}-1$ (Dempsey and Bansal, 2012), were developed: the fluidised bed (Di Matteo et al., 2003; Reynoso and Calvelo, 1985) and the impingement (Salvadori and Mascheroni, 2002; Kaale et al., 2011). In these systems, the adopted air temperature is usually about $-20^{\circ} \mathrm{C}$, since a sufficient heat transfer coefficient between food and air is guaranteed by the high medium velocity. In the fluidised bed, the product is moved through a freezing tunnel on a conveyor grid by an upward and sideways injection of cold air, making the product float and tumble. This technology is used to freeze small-sized food items, such as peas, blueberries, etc. In the impingement technology, cold air is injected with nozzles directly in proximity of the product surface, ensuring a very high heat exchange between the air and the product itself. Although a quick-freezing time is obtained, this technology can only be adopted to process a limited set of foods characterized by small thickness, such as peas, French fries, fruit slices etc. Indeed, large products, characterized by a thickness greater than $25 \mathrm{~mm}$ (Dempsey and Bansal, 2012), could be damaged by the freezer-burn phenomena on the external surface. 
Alternatively, a liquid medium (e.g. $\mathrm{CaCl} 2$ or $\mathrm{C} 2 \mathrm{H} 6 \mathrm{O} 2$ solutions, $\mathrm{CO} 2$, etc.) may be used in food freezing. An advantage of this solution is the enhanced heat transfer, which in the case of liquids is 10 to 20 times higher than the one obtained with air (Galetto et al., 2010; Islam et al., 2014; Xu et al., 2016).

Another solution is based on liquid nitrogen evaporation systems, in which the food is frozen by a mixture of air and nitrogen. The compressed liquid nitrogen is injected through nozzles in batch or tunnel freezers (Awonorin, 1997; Shaikh and Prabhu, 2007; Gazda, 2013) where it rapidly evaporates at ambient pressure, absorbing a large amount of heat from the food. These systems are operated with an open cycle as the refrigerant cannot be recovered at the end of the freezing process (Foster et al., 2011). Therefore, liquid nitrogen systems are characterised by high running costs due to the onerous supplying chain of the refrigerant.

Low temperatures for freezing purposes can also be achieved by means of a reversed Brayton cycle ( $\mathrm{rB}$ cycle) (Chang et al., 2009; Streit and Razani, 2013; Giannetti and Milazzo, 2014). The rB cycle's main components are the compressor, the turbine, and the heat exchanger. A relevant characteristic of the $\mathrm{rB}$ cycle, compared to the direct one, is the different set of working fluid temperatures in the turbomachineries: e.g. in the $\mathrm{rB}$ cycle, the turbine is designed to operate at very low temperatures, even below $100{ }^{\circ} \mathrm{C}$, while in the direct one, the turbine is designed to receive very hot gases at the inlet (about $1200^{\circ} \mathrm{C}$ in power plant stations and $2000^{\circ} \mathrm{C}$ in air craft engines).

Nowadays, the application of the $\mathrm{rB}$ cycle is still limited to a few specific sectors, mainly in the temperature range $[0,10]^{\circ} \mathrm{C}$. This is the case, for example, of air conditioning and cabin pressurisation of airplanes and high-speed trains, and of air cycle heat pumps. In these applications, the advantages of a cooling system based on the $\mathrm{rB}$ cycle are reliability, the reduced dimensions and weight of plant components, and the safety level given by the adoption of air as the working fluid (Rogers, 1994) since it is non toxic, non flammable and with null ozone depletion and global warming potential. The design and performance analysis of aircycle refrigeration systems conducted by Spence et al. $(2004,2005)$ confirmed the profitable application of this system to road transport air conditioning. Other applications of $\mathrm{rB}$ cycles, over $0{ }^{\circ} \mathrm{C}$, concerned air conditioning on ships and for supermarket facilities (Elsayed et al., 2006; Hou et al., 2008). The optimal conditions and different layouts of regenerated air cycle heat pumps were analysed by several authors (see e.g. Bi et al., 2008, 2009, 2012; Ahmadi et al., 2016; Li et al., 2017).

For freezing applications, an open rB cycle was studied by Hou and Zhang (2009), but cold air temperature was limited to $-55^{\circ} \mathrm{C}$. Foster et al. (2011) developed a first closed air cycle cooling and heating prototype able to reach working fluid temperature (air) even lower than $-100^{\circ} \mathrm{C}$ at the outlet of the turbine and at the same time recovering large quantities of heat at a temperature higher than $150{ }^{\circ} \mathrm{C}$ at the compression stage outlet. A compressor-turbine unit, also named bootstrap unit, developed for aircraft air conditioning was used.

The objective of this work is to design a new system based on an innovative modified $\mathrm{rB}$ cycle configuration, able to produce cooling energy at a very low temperature (below $-110^{\circ} \mathrm{C}$ ) with an improved efficiency level. Indeed, facing the limitations of previous published plant concepts, the proposed system is characterised by an enhanced efficiency of the thermodynamic cycle. Together with the description of the design features, a performance evaluation of the proposed freezing plant is hereby presented. With this aim, a numerical model of the system was developed (1) to investigate the performance of the plant at steady-state conditions; (2) to identify which components affect the performance of the plant the most and (3) to optimise the overall thermodynamic cycle (Ahmadi et al., 2014; Ahmadi and Ahmadi, 2016). The proposed plant scheme turns out to be an effective technological alternative to liquid nitrogen freezing plants in very-low temperature freezing processes. 
The paper is structured as follows. Section 2 describes the structure of the reversed Brayton cycle, which is the basis of the new thermodynamic cycle proposed in Section 3. Section 4 describes the modelling framework of the designed modified $\mathrm{rB}$ cycle, which was adopted to perform the sensitive analysis presented in Section 5. The energy performance optimisation and the results are discussed in Section 6, while the conclusions are reported in Section 7.

\section{Introduction to the reversed Brayton cycle}

In a closed reversed Brayton cycle (Fig. 1a), the gaseous working fluid, from the initial condition of pressure $\mathrm{p}_{1 \mathrm{a}}$ and temperature $\mathrm{T}_{1 \mathrm{a}}$, is compressed to pressure $\mathrm{p}_{2 \mathrm{a}}$ by a compressor $(\mathrm{PC})$, which increases its temperature to $\mathrm{T}_{2 \mathrm{a}}$. Then, it is involved in a cooling process through a heat exchanger (HX1) where it releases heat $\mathrm{q}_{\mathrm{HX} 1}$ to a warm region. Once cooled at temperature $\mathrm{T}_{3 \mathrm{a}}$, the working fluid is expanded through a turbine (TB) until it reaches pressure $\mathrm{p}_{1 \mathrm{a}}$ and minimum cycle temperature $\mathrm{T}_{\min , \mathrm{a}}$, low enough to remove heat from the cold region. Indeed, downstream from the turbine and before re-entering the compressor, the working fluid passes through a cold heat exchanger (CHX) where it is heated up by absorbing heat from the region that has to be cooled. The heat $\mathrm{q}_{\mathrm{CL}}$ received by the working fluid in the CHX represents the cooling load of the thermodynamic cycle. Moreover, the working fluid does not change phase during the thermodynamic transformations. By installing the compressor and the turbine on the same shaft, the mechanical work $\mathrm{l}_{\mathrm{CP}}$ required by the compressor can be partially supplied by the mechanical work of turbine $\mathrm{l}_{\text {TB }}$. The resulting mechanical unbalance between driving and resistance forces has to be compensated by an external mechanical power source, such as an electric motor (M). The Gibbs diagram of the cycle is presented in Fig. $1 b$.

Applicative examples of the $\mathrm{rB}$ cycle are mainly referred to as open cycle, where the working fluid is not recovered after the $\mathrm{CHX}$, having been expelled out of the cycle. In aircraft cabin refrigeration and pressurisation, the compressed air can be directly bled from the aircraft engine compressor, avoiding the installation of a dedicated compressor. The bled pressurised air is cooled in a heat exchanger and then, after being expanded by a turbine, is injected in the cabin.

The rB cycle's Coefficient of Performance, assessed by comparing the heat removed from the cold heat exchanger and the work supplied by the electric motor, can be defined as

$\operatorname{CoP}=\frac{h_{1 \mathrm{a}}-h_{4 \mathrm{a}}}{\left(\left(h_{2 \mathrm{a}}-h_{1 \mathrm{a}}\right)-\left(h_{3 \mathrm{a}}-h_{4 \mathrm{a}}\right)\right) \cdot \zeta_{\mathrm{M}}^{-1}}$

where $h$ is the specific enthalpy of the working fluid and $\zeta_{M}$ the efficiency of the electric motor. Temperature value $\mathrm{T}_{\min , \mathrm{a}}$, much lower than $0^{\circ} \mathrm{C}$, cannot be easily obtained in the plant scheme of Fig. 1 , making that configuration unsuitable for freezing processes. A reduction of the temperature at the turbine outlet can be obtained, for example, by reducing the inlet turbine temperature. This task can be performed by adopting a regenerative heat exchanger (RHX) installed to intercept the working fluid exiting the HX1 at one side of the heat exchanger and exiting the $\mathrm{CHX}$ at the other side of the heat exchanger (Fig. 2). This configuration allows lower temperature values $\mathrm{T}_{\min , \mathrm{b}}$ to be achieved after the expansion, making the cooling load $\mathrm{q}_{\mathrm{CL}}$ effective at lower temperatures.

Compared to the cycle represented in Fig. 1, this configuration has a lower CoP, considering all the unchanged cycle parameters (e.g. the same compressor ratio, the same isentropic efficiency of the turbo machineries, the same inlet compressors pressure and temperature and the same $q_{\mathrm{CL}}$ ). Even if the efficiency of the thermodynamic cycle of Fig. 2 is reduced, it should be noted that the introduction of an $\mathrm{RHX}$ is essential to achieve the required low temperature at the turbine outlet. Working at lower 
temperatures, the mechanical unbalance between turbine and compressor increases, leading to an unfavourable increment of the required external mechanical power.

\section{Modified reversed Brayton cycle}

To comply with the discussed technical features of standard rB cycles and to overcome the limitations of plant configurations presented in literature (see $\S 1$.), an innovative modified $r B$ cycle has been designed. The proposed cycle involves new features regarding the scheme configuration (Fig. 3), the temperature and pressure levels of the primary circuit, the adopted working fluid and, finally, the food freezing process technique.

The proposed freezing plant can be outlined into two sub-systems: (1) a primary closed system, operated by an rB cycle, which cools a gaseous working fluid at very low temperatures and (2) a secondary system, where food is processed by batch in a freezer room by controlled recirculation of cold air. A cold heat exchanger ( $\mathrm{CHX}$ ), where the medium fluid (air) of the secondary loop is cooled by the working fluid of the primary closed loop, connects the two systems. The modified rB cycle has been designed to ensure a mean operative air temperature of the batch freezer of about $-80^{\circ} \mathrm{C}$.

In the loop, the presence of chemical compounds with freezing point above the lowest temperature of the system is a critical problem due to the possibility of solids formation (e.g. ice, in case of moisture) that may lead to serious damage and/or malfunctions of the mechanical components (first of all, the turbine). As a trace of moisture is usually released by the food during the freezing process, the modified $\mathrm{rB}$ cycle working fluid cannot be directly used inside the freezing room. This leads to the adoption of two separate systems. To further reduce the occurrence of icing in the primary loop, the adoption of an anhydrous working fluid (e.g. nitrogen) has been conceived. The design of two distinct systems also allows the operation of the modified rB cycle at loop pressure, which is always greater than $101 \mathrm{kPa}$, which allows (1) to improve cycle efficiency; (2) to reduce pipe and heat exchangers sizes and (3) to prevent external (moist) air infiltration in the loop. The problem of ice formation cannot be completely avoided in the batch freezer: in addition to the moisture released by the food and absorbed by the medium fluid, moist air from the environment enters the freezer during door opening and food loading and unloading. A defrosting procedure of the $\mathrm{CHX}$ is thus required to remove ice formation on the cold surfaces and to prevent heat exchange rate degradation.

More in detail, the compression of the working fluid has been divided into two separate stages. The first compression is performed by a bootstrap unit, which is constituted by the compressor (BC) and the turbine (TB), installed on the same shaft. In this configuration, the mechanical work required by the bootstrap compressor is completely supplied by the turbine. The second compression stage is then performed by the primary compressor (PC), which is driven by an electric motor (M). In order to reduce the required electric power, the working fluid is cooled, from $\mathrm{T}_{2 c}$ to $\mathrm{T}_{3 c}$, by the heat exchanger HX1 placed between the two compressors. Once compressed at pressure $\mathrm{p}_{4 c}$, and before entering the turbine, the working fluid is cooled down in the second heat exchanger (HX2) and in the regenerative heat exchanger RHX, reaching temperature $\mathrm{T}_{6 \mathrm{c}}$. Water cools the HX1 and HX2. Downstream from the turbine and before re-entering the compressor BC, the working fluid passes through the cold heat exchanger (CHX) installed in the batch freezer and, finally, through the second duct of the RHX. In the CHX, the working fluid cools the air in the batch freezer by absorbing $\mathrm{q}_{\mathrm{CL}}$.

Differently from Foster et al.'s (2011) system, where the compression of the working fluid is sequentially performed by the primary compressor followed by the bootstrap unit, in the proposed plant layout the primary compressor is installed after the bootstrap unit to obtain a reduction of the working temperature 
gap among the components. The gaseous working fluid was selected to avoid solids formation in the colder components of the plant and, in addition, the minimum pressure value of the $r B$ cycle ( $B C$ inlet) should be higher than the atmospheric one, allowing an increase in cycle performance.

The CoP of the proposed plant configuration is defined as

$C o P=\frac{h_{8 \mathrm{c}}-h_{7 \mathrm{c}}}{\left(h_{4 \mathrm{c}}-h_{3 \mathrm{c}}\right) \cdot \zeta_{\mathrm{M}}^{-1}}$

which is the ratio of the working fluid enthalpy differences in the $\mathrm{CHX}$ and in the $\mathrm{PC}$, taking into account the electric motor efficiency $\zeta_{M}$.

Since in the food industry hot water and/or steam are typically required for several thermal processes - e.g. blanching (Xin et al., 2015), cooking, washing, heating (Comba et al., 2010; Comba et al., 2011; Biglia et al., 2015), pasteurisation, debacterisation (Biglia et al., 2017), etc. - the heat released by the working fluid in the HX1 and HX2 may be favourably recovered, as demonstrated and tested in the air cycle prototype developed by Foster el at. (2011). In particular, the heat supplied by the HX1 may be used to warm a fluid, generally water, up to $[40,60]^{\circ} \mathrm{C}$ while the thermal level of the heat available in the HX2 might even allow production of low-pressure steam. In addition, the rejected heat from the HX1 and HX2 may also be used for space heating or to pre-heat water entering a boiler. Considering the concurrent cooling and heating effect production, heat recovery (Ashrafi et al., 2015) represents a relevant advantage of $r B$ cycles with respect to other freezing technologies, such as liquid nitrogen evaporation.

\section{Plant modelling framework}

A numerical model of the proposed modified rB cycle plant (Fig. 3) has been developed in order to evaluate the energy performance of the freezing plant. Each component was modelled by using the conservation of energy for one-inlet one-outlet control volume with one-dimensional flow (Moran and Shapiro, 2006). In particular, steady-state conditions were considered and heat losses across the components as well as potential and kinetic energy terms were neglected. Moreover, given the required level of detail, pressure drops were considered constant in the heat exchangers and null in the connection pipes. The thermodynamic state of the working fluid, in terms of temperature and/or pressure values, in a set of loop nodes was defined by physical and plant constructive constraints.

The model was implemented by using the Matlab ${ }^{\circledR}$ environment (version R2015b). Since the system of nonlinear equations describing the thermodynamic and mechanic equilibrium among the loop components cannot be solved analytically, the Levenberg-Marquardt numerical solving method was adopted. The thermodynamic properties of gaseous nitrogen, adopted as the working fluid in the loop, were evaluated by integrating the Reference Fluid Thermodynamic and Transport Properties (REFPROP) database, developed by the National Institute of Standards and Technology (NIST, version 9.1), directly with the model framework of the plant.

It should be noted that all the results were normalised by the cooling load $\dot{Q}_{\mathrm{CL}}$.

\subsection{Thermodynamic model of the components}

The steady state form of the energy rate balance has been used to develop the thermodynamic model of the plant's components. The energy rate balance of the compressors (and - analogously - of the turbine) can be expressed as

$\dot{W}=\dot{m}_{\mathrm{N}}\left(h_{\text {in }}-h_{\text {out }}\right)$ 
where $h_{\text {in }}$ and $h_{\text {out }}$ account for the specific enthalpy of the nitrogen mass flow rate $\dot{m}_{N}$ at the component inlet and outlet, respectively, and $\dot{W}$ is the net rate of energy transfer by work across the turbo machinery. The specific enthalpy difference $h_{\text {in }}-h_{\text {out }}$ is related to the pressure ratio $\beta$ and to the isentropic efficiency $\eta$ of the turbo machinery, in addition to the thermodynamic properties of the fluid.

With the same approach, the net heat rate across the heat exchangers can be expressed as

$\dot{Q}=\dot{m}_{\mathrm{N}}\left(h_{\text {in }}-h_{\text {out }}\right)$

In this case, the specific enthalpy difference $\mathrm{h}_{\text {in }}-\mathrm{h}_{\text {out }}$ depends on the pressure drops $\Delta \mathrm{p}$ and on the effectiveness $\varepsilon$ of the heat exchanger. The balance equations of each loop component (Fig. 3) are summarised in Table 1.

Parameters $\dot{W}$ and $\dot{Q}$ of each component were normalised per unit of cooling load $\dot{Q}_{\mathrm{CL}}$.

\subsection{Thermodynamic constraints and specifications}

The set of feasible working parameters of the modified $\mathrm{rB}$ cycle is constrained by the technical specifications of the components and/or by the boundary conditions. The constraints considered in the model implementation concerned:

- nitrogen pressure at the compressor $B C$ inlet $\mathrm{p}_{1 \mathrm{c}}$ and at the compressor PC outlet $\mathrm{p}_{4 \mathrm{c}}$. The atmospheric pressure, to avoid external moist air infiltration, was considered to be the limit for the minimum pressure of the plant $p_{1 c}$. The maximum value of pressure $p_{4 c}$ was limited to fulfil the mechanical constraints due to the resistance of the heat exchangers, which is usually referred to about $3 \mathrm{MPa}$. Therefore, the pressure of the plant is subject to both upper and lower boundary conditions;

- nitrogen temperatures $T_{3 c}$ and $T_{5 c}$ at the outlet of heat exchangers $H X 1$ and $H X 2$ respectively. The values of $\mathrm{T}_{3 \mathrm{c}}$ and $\mathrm{T}_{5 \mathrm{c}}$ are related to the temperature of the cooling fluid and to the technology adopted in the HX1 and $H X 2$. Assuming the $H X 1$ and $H X 2$ are cooled by using water at $30^{\circ} \mathrm{C}$ (standard operating temperature of the cooling water tower) and considering a pinch point of $10^{\circ} \mathrm{C}$ between the inlet cooling water and the outlet cooled nitrogen, temperatures $T_{3 c}$ and $T_{5 c}$ were considered fixed;

- the isentropic efficiency of turbo machineries $\eta_{\mathrm{BC}}, \eta_{\mathrm{PC}}, \eta_{\mathrm{TB}}$. Even if the fine tuning of the machines efficiency values is affected by the power size of the components and the adopted technical solution, these values were considered constant and equal to standard design values for such types of components;

- the effectiveness of the regenerator RHX. The regenerator effectiveness $\varepsilon$ RHX was considered constant in the thermodynamic model of the plant;

- the operating parameters of the cold heat exchanger CHX. In particular, the outlet nitrogen temperature $\mathrm{T}_{8 \mathrm{c}}$, the nitrogen temperature difference $\Delta \mathrm{T}_{\mathrm{CHX}}$ between the inlet and the outlet of the $\mathrm{CHX}$ and the cooling load $\dot{\mathrm{Q}}_{\mathrm{CL}}$ were considered constant.

\subsection{Cycle equilibrium solution}

A different regulation of the energy converters was studied to evaluate possible energy savings of the existing plant shown in Fig. 3.

The setting of the plant parameters must guarantee the mechanical and thermodynamic balance between plant components. Due to the relationships and the constraints linking the nitrogen thermodynamic states (§ 4.2), the pressure ratios $\beta_{\mathrm{BC}}$ and $\beta_{\mathrm{PC}}$ of the bootstrap and the primary compressor have been assumed 
as design variables (independent variables). Indeed, the bootstrap and primary compressor working pressures affect the bootstrap unit mechanical balance according to

$\dot{m}_{\mathrm{N}}\left(h_{6 \mathrm{c}}\left(T_{6 c}, p_{1 \mathrm{c}} \beta_{\mathrm{BC}} \beta_{\mathrm{PC}}\right)-h_{7 \mathrm{c}}\left(T_{7 \mathrm{c}}, p_{7 \mathrm{c}}\right)\right)=\frac{\dot{m}_{\mathrm{N}}\left(h_{2 \mathrm{c}}\left(T_{2 \mathrm{c}}, p_{1 \mathrm{c}} \beta_{\mathrm{BC}}\right)-h_{1 \mathrm{c}}\left(T_{1 \mathrm{c}}, p_{1 \mathrm{c}}\right)\right)}{f_{\mathrm{BU}}}$

and the turbine isentropic efficiency

$\eta_{\mathrm{TB}}=\frac{h_{6 \mathrm{c}}-h_{7 \mathrm{c}}}{h_{6 \mathrm{c}}-h_{7 \mathrm{c}, \mathrm{is}}}=\frac{h_{6 \mathrm{c}}\left(T_{6 \mathrm{c}}, p_{1 \mathrm{c}} \beta_{\mathrm{BC}} \beta_{\mathrm{PC}}\right)-h_{7 \mathrm{c}}\left(T_{7 \mathrm{c}}, p_{7 \mathrm{c}}\right)}{h_{6 \mathrm{c}}\left(T_{6 \mathrm{c}}, p_{1 \mathrm{c}} \beta_{\mathrm{BC}} \beta_{\mathrm{PC}}\right)-h_{7 \mathrm{c}}\left(T_{7 \mathrm{c}, \mathrm{is}}, p_{7 \mathrm{c}}\right)}$

where $f_{\mathrm{BU}}$ and $h_{\mathrm{is}}$ account for the mechanical losses in the bootstrap and the isentropic specific enthalpy respectively. The values of pressure ratios $\beta_{\mathrm{BC}}$ and $\beta_{\mathrm{PC}}$, which guarantee the solution of non-linear equations (5) and (6), were numerically obtained by means of a Levenberg-Marquardt algorithm, implemented in Matlab ${ }^{\circledR}$.

\section{Dynamic Energy performance analysis of the modified rB cycle}

The effect of a set of thermodynamic parameters on the energy efficiency of the modified rB cycle, measured by the CoP index (Eq. 2), was investigated by means of a performance analysis. In order to quantify the individual effect of a parameter on the overall system performance, the behaviour of the plant was simulated for a set of configurations generated by varying only one parameter at a time, within a specified range, while keeping all the others constant. During new systems design, performance analysis is an effective tool to identify the plant components which affect system efficiency the most, with the aim of properly focusing improvement efforts, and of obtaining preliminary results by helping system optimisation. The performance analysis was carried out on the modified rB cycle operated with the thermodynamic parameters listed in Table 2.

\subsection{Effect of the system's pressurisation}

In order to assess the effect of the working fluid pressure on system performance, the CoP was computed for a set of plant configurations with loop minimum pressure $p_{1 c}$ varying within the range $[100,1000] \mathrm{kPa}$. The resulting growing trend of the modified $\mathrm{rB}$ cycle efficiency, related to increments of the $\mathrm{p}_{1 \mathrm{c}}$ value (Fig. $4 a$ ), is due to the reduction of the required pressure ratio $\beta_{\mathrm{PC}}$ of the primary compressor (Fig. $4 \mathrm{~b}$ ) and to the increment in the working fluid density, which lead to a reduction in the required compression work (Fig. 4c). Since the incremental rate of the system's performance due to loop pressurisation significantly decreases for $\mathrm{p}_{1 \mathrm{c}}$ values above $500 \mathrm{kPa}$ (Fig 4a), the pressurisation of the system may be settled to a value which benefits the CoP and to the required mechanical resistance of the plant components.

The heat exchangers' normalised capacity per unit of cooling load is reported in Fig. $4 \mathrm{~d}$. The pressurisation of the system mainly affects the capacity of the heat exchanger $\mathrm{HX} 2$, which decreases with an increment of $p_{1 c}$, while the capacities of exchangers $\mathrm{HX} 1$ and RHX can be considered constant according to the adopted hypothesis. Since the temperatures $T_{3 \mathrm{c}}$ and $T_{5 \mathrm{c}}$ at the PC inlet and HX2 outlet respectively are fixed and equal in value, the result is a comparable trend of the normalised power of the two consecutive loop components (Figs. 4c, 4d). For $p_{1 \mathrm{c}}$ values above $500 \mathrm{kPa}$, the normalised power $\dot{W}_{\mathrm{PC}}$ required by the PC is about 3 times larger than the one required by the BC, while the capacity of heat exchangers HX2 and RHX is about 4 times larger than the one of the HX1. 


\subsection{Effect of the working fluid's temperature at the HX1 and HX2 outlets}

The effect of the nitrogen temperature at the outlets of heat exchangers HX1 and HX2 on the system's CoP was investigated by simulating the modified $r B$ cycle behaviour by varying $T_{3 c}$ and $T_{5 c}$, values within the range $[30,50]^{\circ} \mathrm{C}$ (Fig. 5a). A slight reduction of the plant's CoP can be noted with higher $T_{3 \mathrm{c}}$ and $T_{5 \mathrm{c}}$ temperature values. Indeed, an increment of $T_{3 \mathrm{c}}$ corresponds to an intercooling reduction between the two nitrogen compression stages, which leads the mechanical work of the compressor PC to increase. The effect of $T_{5 \mathrm{c}}$ on the whole system's CoP is more complex and can be linked to the changes led to the thermodynamic state of the working fluid at the turbine TB inlet. Indeed, with constant regenerator effectiveness $\varepsilon_{\mathrm{RHX}}$, an increment in the $T_{5 \mathrm{c}}$ value determines a resulting turbine inlet temperature $T_{6 \mathrm{c}}$ increment. In order to maintain the cooling load constant, which results in a fixed temperature $T_{7 \mathrm{c}}$ and pressure $p_{7 \mathrm{c}}$ at the turbine outlet, an increment of temperature $T_{6 \mathrm{c}}$ requires a higher $p_{6 \mathrm{c}}$ value before the nitrogen expansion. The resulting slight increments $\beta_{\mathrm{TB}}$ and $\beta_{\mathrm{PC}}$ (Fig. 5b) lead to a CoP reduction.

Temperatures $T_{3 \mathrm{c}}$ and $T_{5 \mathrm{c}}$ may be set as low as possible, according to the adopted typology of heat exchangers $\mathrm{HX} 1$ and $\mathrm{HX} 2$ and to the cooling fluid mass flow rate and temperature. Within the considered temperature range of $T_{3 \mathrm{c}}$ and $T_{5 \mathrm{c}}$, the mechanical power of turbo-machineries (Fig. $5 \mathrm{c}$ ) does not change significantly with respect to the heat exchanger's capacity (Fig. 5d): an increment of the nitrogen temperature at the outlet of one heat exchanger (HX1 or HX2) leads to a reduction of its capacity, while a capacity increment of all the others is required to balance the loop equilibrium.

\subsection{Effect of the working fluid's temperature gap in the CHX}

The variation of the plant's CoP was analysed by considering a working fluid temperature difference $\Delta \mathrm{T}_{\mathrm{CHX}}$ between the heat exchanger $\mathrm{CHX}$ inlet and outlet varying within the range $[20,70]^{\circ} \mathrm{C}$. The efficiency of the modified $\mathrm{rB}$ cycle is deeply sensitive to the $\Delta \mathrm{T}_{\mathrm{CHX}}$ parameter (Fig. $6 \mathrm{a}$ ), showing a non-monotonous trend with a maximum value within the considered range of values. By affecting both the required nitrogen flow rate $\dot{\mathrm{m}}_{\mathrm{N}}$ and the outlet turbine temperature $\mathrm{T}_{7 \mathrm{c}}$, the effect of $\Delta \mathrm{T}_{\mathrm{CHX}}$ on system performance is relevant. Indeed, given a certain cooling load $\dot{\mathrm{Q}}_{\mathrm{CL}}$, the product of the nitrogen mass flow rate $\dot{\mathrm{m}}_{\mathrm{N}}$ and $\Delta \mathrm{h}(\Delta \mathrm{T}, \Delta \mathrm{p})_{\mathrm{CHX}}$ must be constant. Benefits to the overall CoP value can be achieved with low $\dot{\mathrm{m}}_{\mathrm{N}}$ values, which involve a low turbo machineries power $\dot{W}$ (Fig. $6 \mathrm{c}$ ), and/or a low $\Delta \mathrm{T}_{\mathrm{CHX}}$ value, which corresponds to a higher $\mathrm{T}_{7 \mathrm{c}}$ temperature at the turbine outlet and, thus, a reduction of the turbine pressure ratio $\beta_{\mathrm{TB}}$ (Fig. $6 b)$. The positive effect of this last phenomenon to the system's CoP can be easily attributed to the required lower pressure ratio $\beta_{\mathrm{PC}}$ of the primary compressor (Fig $6 \mathrm{~b}$ ). Therefore, the correct choice of $\Delta \mathrm{T}_{\mathrm{CHX}}$ allows the performance of the system to be maximised.

Fig. $6 \mathrm{~d}$ shows the capacity of the heat exchangers per unit of cooling load as a function of the temperature difference in the $\mathrm{CHX}$. It can be noticed that the capacity of the HX1 is constant compared to the increase of $\Delta T_{\mathrm{CHX}}$.

\subsection{Effect of the turbo-machineries' isentropic efficiency}

The sensitivity of the system's CoP to the isentropic efficiency of the compressors and of the turbine was evaluated for a set of plant configurations with $\eta_{\mathrm{PC}}$ varying within the range $[0.65,0.71], \eta_{\mathrm{BC}}$ within the range $[0.70,0.75]$ and, finally, $\eta_{\mathrm{TB}}$ within the range $[0.78,0.84]$. Even if, of course, a positive effect on the CoP was found in connection to an increment of all the turbo machineries efficiencies (Fig. 7a), the CoP turned out to be more affected by the isentropic efficiency of the primary compressor and of the turbine, compared to the bootstrap compressor. 
More in detail, considering a constant cooling load $\dot{Q}_{\mathrm{CL}}$, the adoption of bootstrap components $-\mathrm{BC}$ and TB - with higher isentropic efficiency values, allows a PC pressure ratio $\beta_{\mathrm{PC}}$ reduction (Fig. 7b). Indeed, given a fixed thermodynamic state at the turbine outlet and an invaried mechanical power balance at the bootstrap unit shaft (Fig. $7 \mathrm{C}$ ), an increment in $\eta_{\mathrm{BC}}$ and $\eta_{\mathrm{TB}}$ lets the pressure ratio and the mechanical power of the primary compressor to decrease. Even if $\eta_{B C}$ has a minor effect on the overall system's performance with respect to $\eta_{\mathrm{TB}}$, an increment in its value would allow the mechanical power supplied by the turbine to be more effective, leading to favourable $\beta_{\mathrm{BC}}$ increments and $\beta_{\mathrm{PC}}$ reductions.

The isentropic efficiency $\eta_{\mathrm{PC}}$ of the primary compressor mainly affects the required electric power and, thus, the system's CoP (Fig. 7a and 7c).

Regarding the power and heat capacity of the cycle components, it should be noted that an increment in the turbo-machineries isentropic efficiency leads to a significant reduction in the sole primary compressor power (Fig. 7c) and in the capacity of heat exchanger HX2 (Fig. 7d). On the contrary, the normalised power per unit of cooling load of the bootstrap unit (Fig. 7c) and the capacity per cooling load of heat exchangers HX1 and RHX (Fig. 7d) are less affected since temperatures $T_{3 c}, T_{5 c}, T_{8 \mathrm{c}}$ and the lower pressure $p_{1 \mathrm{c}}$ are fixed parameters.

\subsection{Effect of the regenerator's effectiveness}

The effect of regenerator effectiveness $\varepsilon_{\mathrm{RHX}}$ on the modified $\mathrm{rB}$ cycle performance was investigated by varying its value within the range [0.90, 0.95]. An increment of the system's CoP (Fig. 8a) can be obtained by increasing regenerator effectiveness. Indeed, given regenerator inlet temperatures $T_{5 \mathrm{c}}$ and $T_{8 \mathrm{c}}$ of the hot and cold sides respectively, higher $\varepsilon_{\mathrm{RHX}}$ values lead to a reduction of nitrogen temperatures $T_{6 \mathrm{c}}$ and $T_{1 \mathrm{c}}$ at the RHX outlets, allowing the turbine and bootstrap compressors to work with lower inlet temperatures and, consequently, with lower pressure ratios $\beta_{\mathrm{TB}}$ and $\beta_{\mathrm{BC}}$, to fulfil the imposed constant cooling load $\dot{Q}_{\mathrm{CL}}$. Thus, the turbo machineries' normalised power per cooling load decreases with higher $\varepsilon_{\mathrm{RHX}}$ values (Figs. 8b, 8c). The capacity $\dot{Q}_{\mathrm{HX} 1}$ per unit of cooling load of the HX1 is less affected by $\varepsilon_{\mathrm{RHX}}$ (Fig. 8d), while the capacity $\dot{Q}_{\mathrm{HX} 2}$ of heat exchanger $\mathrm{HX} 2$ and $\dot{Q}_{\mathrm{RHX}}$ of the regenerator decrease and increase, respectively.

\section{Energy performance optimisation}

An optimisation algorithm was coupled with the cycle equilibrium solver (§ 4.3) to identify the best configuration of the modified rB cycle. In line with the results of the performance analysis (§ 5 ), the most effective variables on the system's CoP were considered for the optimisation model. These are:

- Temperature difference in the $\mathrm{CHX}: \Delta \mathrm{T}_{\mathrm{CHX}}$

- Minimum pressure of the loop: $\mathrm{p}_{1 \mathrm{c}}$

- Turbo machineries isentropic efficiency: $\eta_{\mathrm{BC}}, \eta_{\mathrm{PC}}, \eta_{\mathrm{TB}}$

- Regenerator effectiveness: $\varepsilon_{\mathrm{RHX}}$

and can be arranged as $\mathrm{x}=\left[\Delta \mathrm{T}_{\mathrm{CHX}}, \mathrm{p}_{1 \mathrm{c}}, \eta_{\mathrm{BC}}, \eta_{\mathrm{PC}}, \eta_{\mathrm{TB}}, \varepsilon_{\mathrm{RHX}}\right]^{\mathrm{T}}$. The lower and upper bounds for each variable, summarised in Table 3, were set according to the performance analysis and component specifications. Constant parameters used in the optimisation problem were also reported in Table 3. The optimisation problem can be expressed as $\max _{\mathrm{x}} \mathrm{f}(\mathrm{x})$ where

$f(x)=\frac{h_{8 c}-h_{7 c}}{\left(h_{4 c}-h_{3 c}\right) \cdot \zeta_{\mathrm{M}}^{-1}}$

which represents the plant's CoP of Fig. 3. 
The optimisation solver was implemented in the Matlab ${ }^{\circledR}$ by adopting an interior-point method developed to solve nonlinear optimisation problems.

\subsection{Optimisation results}

The highest value of the system's CoP, obtained by the optimisation process, is equal to 0.322 , which involves an electric engine power of $3.11 \mathrm{~kW}$ per unit of cooling load in the $\mathrm{CHX}$. This plant configuration is characterised by the minimum pressure value of the system, turbo machineries isentropic efficiency and regenerator effectiveness equal to the prescribed upper bound of Table 3 , while the final $\Delta \mathrm{T}_{\mathrm{CHX}}$ value is $28.9^{\circ} \mathrm{C}$. The set of optimal parameters can be summarised as $\mathrm{x}_{\text {opt }}=[28.9,1000,0.75,0.71,0.84,0.95]^{\mathrm{T}}$. The thermodynamic state of each loop node, in terms of nitrogen temperature and pressure values, of the obtained operating conditions of the modified $\mathrm{rB}$ cycle is reported in Table 4, together with the normalised net rate of energy transfer by work and heat across the loop components. The resulting value of the nitrogen mass flow rate is also provided in Table 4. The maximum and minimum temperatures of the cycle account for $131.2^{\circ} \mathrm{C}$ and $-113.9^{\circ} \mathrm{C}$, which are reached at the primary compressor $\left(\mathrm{T}_{4 \mathrm{c}}\right)$ and turbine $\left(\mathrm{T}_{7 \mathrm{c}}\right)$ outlets respectively. The maximum pressure of the cycle (primary compressor outlet, $\mathrm{p}_{4 \mathrm{c}}$ ) results in 2494 $\mathrm{kPa}$, within the considered upper pressure limit prescribed for heat exchangers. The normalised mechanical power of the bootstrap compressor, of the primary compressor and of the turbine account for 1.03, 2.95 and 1.12 respectively. Please note that the normalised mechanical power of the primary compressor and the electric engine power are connected to the efficiency of the electric engine. The required turbine power is larger than the power of the bootstrap compressor to balance the mechanical losses of the bootstrap unit.

In addition to the cooling load supply, which is effective at very low temperatures in the CHX, a normalised thermal power of $0.84 \mathrm{~kW}$ and $3.02 \mathrm{~kW}$, per each $\mathrm{kW}$ of cooling load, may be profitably recovered from the $\mathrm{HX} 1$ and in the $\mathrm{HX} 2$ respectively. It should be noted that the thermal level is different in the two heat exchangers (about $65^{\circ} \mathrm{C}$ in the $\mathrm{HX} 1$ and $130^{\circ} \mathrm{C}$ in the $\mathrm{HX}$ ); therefore, depending on the end-user, different plant configurations may be adopted to profitably recover the available heat in the HX1 and HX2. Considering an electricity price for industrial users of $0.16 € \cdot k W h-1$ (average commercial price in Italy, 2016), the running cost of the proposed plant can be estimated at $0.50 € \cdot k W h-1$. This value is lower than a liquid-nitrogen plant running cost of $2.71 € \cdot k W h-1$, obtained by calculating the required liquid nitrogen mass per unit of cooling load, considering a nitrogen latent heat (at saturation conditions at ambient pressure) of $199.44 \mathrm{~kJ} \cdot \mathrm{kg}-1$ and a liquid nitrogen cost of $0.15 € \cdot \mathrm{kg}-1$ (average commercial price in Italy, 2016).

\section{Conclusions}

The performance analysis of an innovative system, based on a modified reversed Brayton cycle, for food freezing at very low temperatures was investigated in this paper. The analysis showed the effect of the different design parameters on the thermodynamic cycle's CoP. The system can achieve very low temperatures (even lower than $-100^{\circ} \mathrm{C}$ ) which are favourable for food fast freezing processes. Gaseous nitrogen was selected as the working fluid of the reversed Brayton cycle, to avoid solids formation in the coolest part the thermodynamic cycle. The food freezing process takes place in a batch freezer room, by means of recirculating air, cooled down by the primary working fluid.

A Coefficient of Performance of 0.322 was obtained by setting the cold heat exchanger (CHX) of the reversed Brayton cycle at an operating average temperature of $-99.5^{\circ} \mathrm{C}$. In particular, the performance analysis showed that the performance of the thermodynamic cycle strictly depends on the pressure level of 
the system, on the temperature difference through the cold heat exchanger and on the effectiveness of the regenerative heat exchanger. This latter component is essential to reach low temperatures at the turbine outlet of the thermodynamic cycle.

As a benefit, large quantities of waste heat, around $3.8 \mathrm{~kW}$ per unit of cooling load, may be recovered and used to produce heated water, which is widely adopted in the food industry (e.g. pre-cooking, blanching, heating, pasteurisation, etc.). In particular, $0.8 \mathrm{~kW}$ and $3 \mathrm{~kW}$ of waste heat per unit of cooling load may be available at temperatures of $65^{\circ} \mathrm{C}$ and $130^{\circ} \mathrm{C}$ respectively.

Considering an electricity cost of $0.16 € \cdot \mathrm{kWh}-1$, a running cost of $0.50 € \cdot \mathrm{kWh}-1$ was estimated for the designed system. This value is lower than the estimated running cost of a liquid nitrogen plant, which is about $2.71 € \cdot k W h-1$.

The proposed innovative food freezing system proves that it is possible to overcome the discussed limitations of the existing reversed Brayton cycle solutions assuring, in the meanwhile, favourable energy performance for food freezing purposes with respect to available technological solutions for food processing at low temperatures.

\section{Figures}

a)

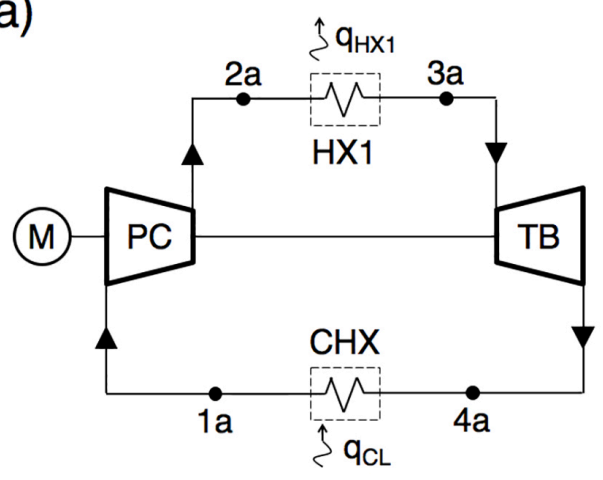

b)

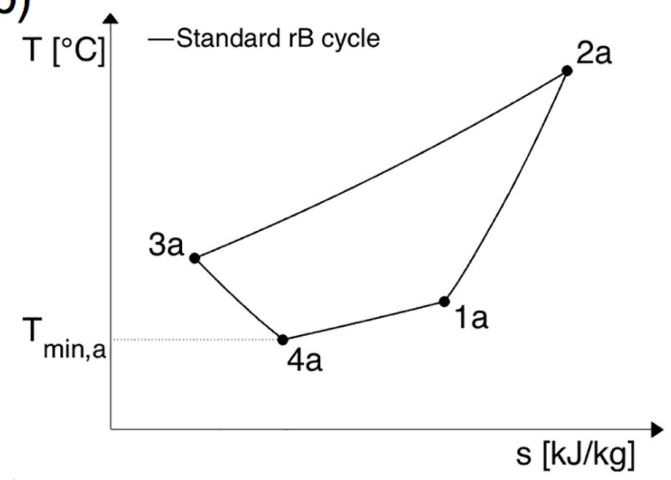

Fig. 1. Standard rB cycle scheme (a) and Gibbs diagram (b). The working fluid, sequentially, undergoes a compression (1a-2a), a cooling phase (2a-3a), an expansion process (3a-4a) and, finally, once the lowest temperature of the cycle $\mathrm{T}_{\mathrm{min}, \mathrm{a}}$ is reached, the fluid is heated removing heat $\mathrm{q}_{\mathrm{CL}}$ from the cooled volume (4a1a).
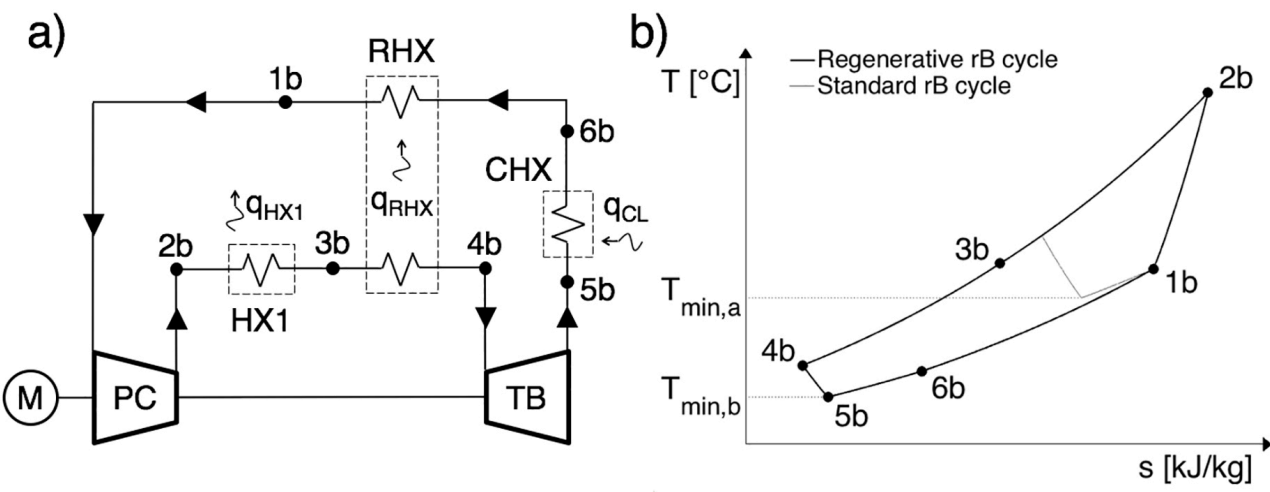

Fig. 2. Regenerative rB cycle scheme (a) and Gibbs diagram (b). 
a)

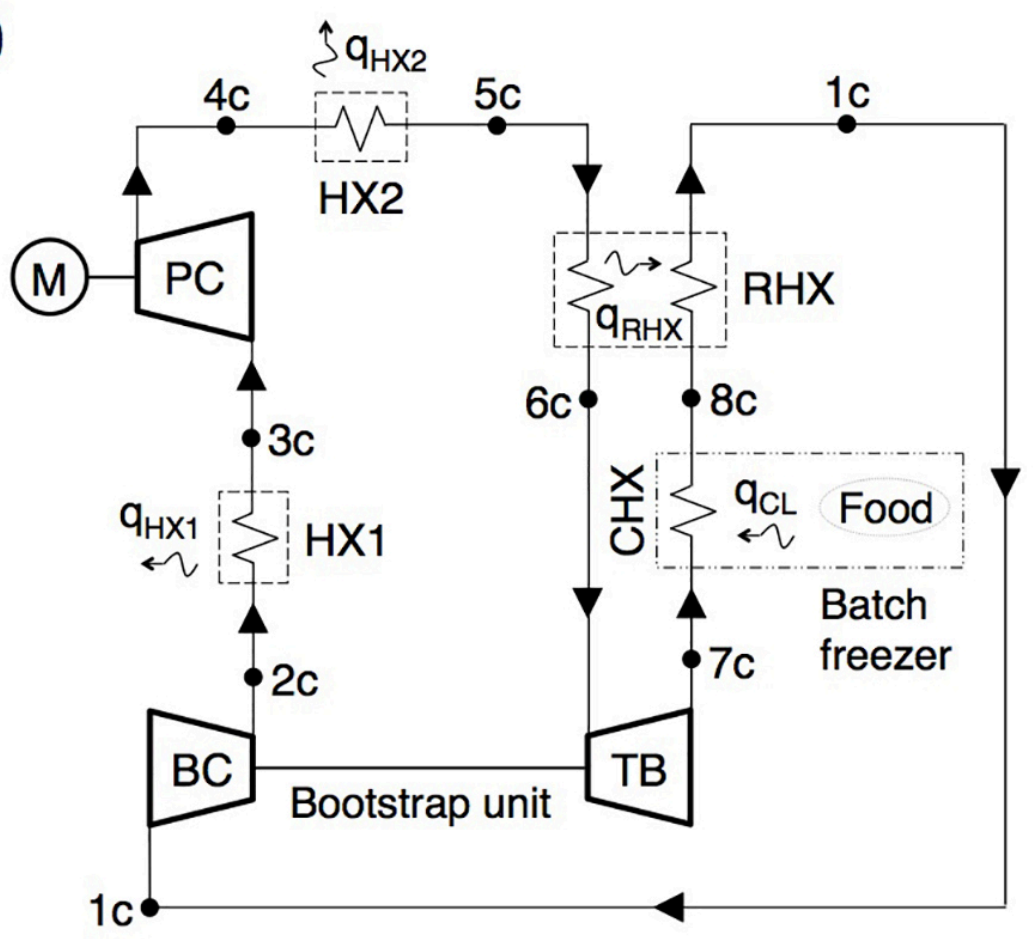

b)

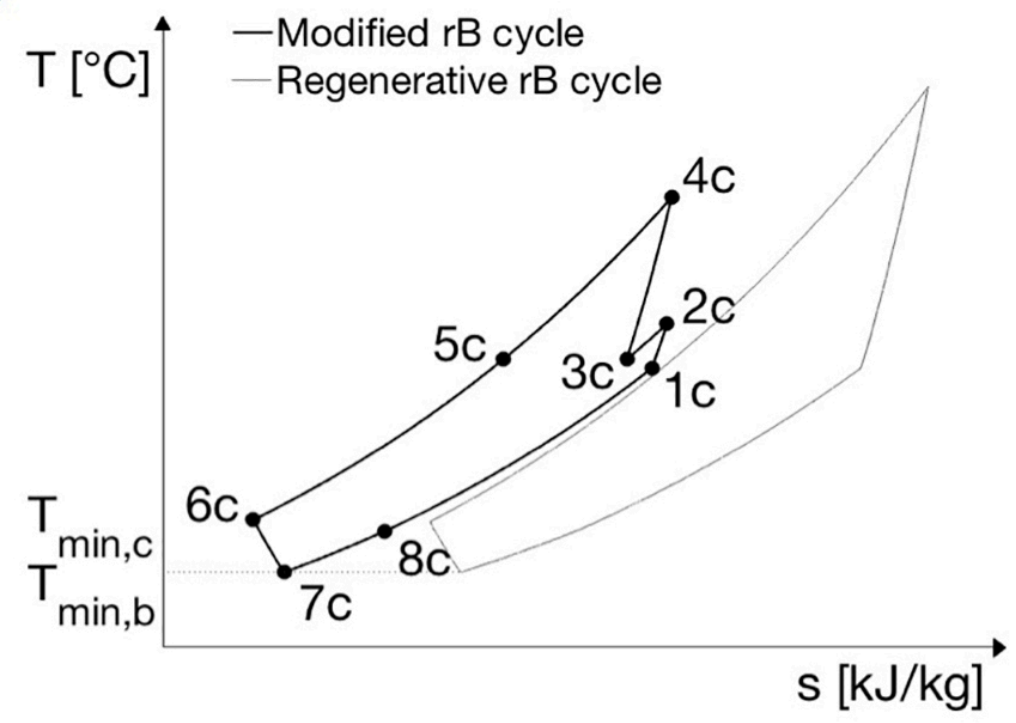

Fig. 3. Innovative modified $\mathrm{rB}$ cycle scheme (a) and Gibbs diagram (b). The working fluid compression phase occurs in $\mathrm{BC}(1 \mathrm{c}-2 \mathrm{c})$ and $\mathrm{PC}(3 \mathrm{c}-4 \mathrm{c})$, with the introduction of an intercooling (2c-3c). Once compressed, the working fluid is sequentially cooled in HX2 (4c-5c) and in RHX (5c-6c), and then expanded in TB (6c-7c). The resulting cold working fluid is reheated in CHX, by absorbing heat from the batch freezer $(7 \mathrm{c}-8 \mathrm{c})$, and in RHX (8c-1c). 
a)

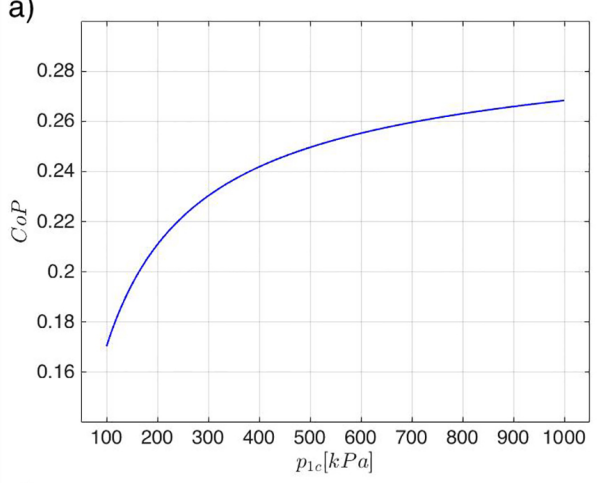

c)

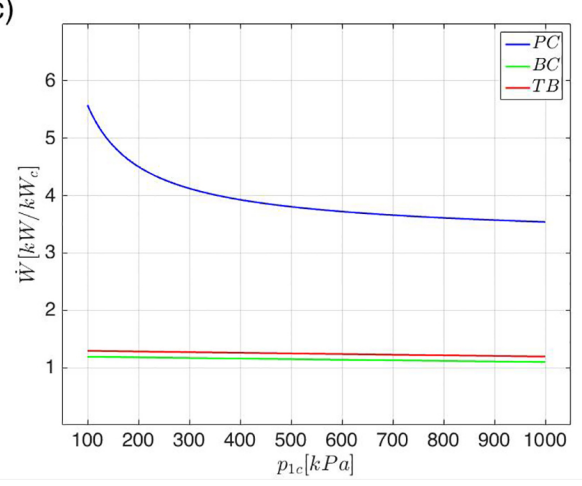

b)

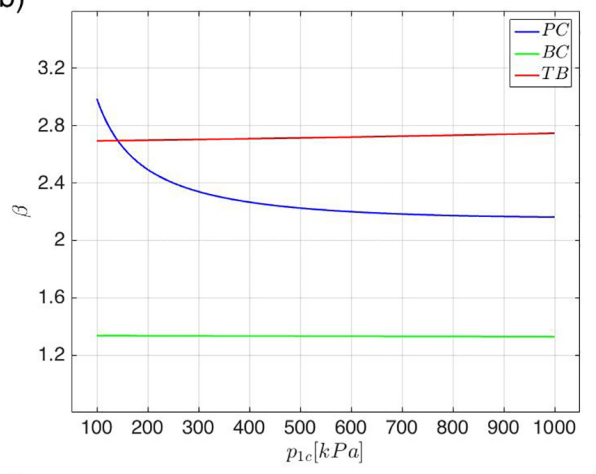

d)

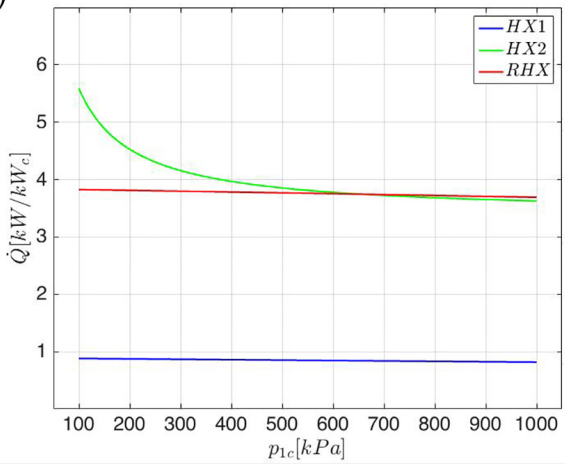

Fig. 4. Effect of the system's pressurisation on the modified rB cycle CoP (a), turbo-machineries pressure ratios $\beta_{\mathrm{PC}}, \beta_{\mathrm{BC}}$ and $\beta_{\mathrm{TB}}(\mathrm{b})$, normalised power $\dot{\mathrm{W}}_{\mathrm{PC}}, \dot{\mathrm{W}}_{\mathrm{BC}}$ and $\dot{\mathrm{W}}_{\mathrm{TB}}$ (c) and, finally, on the heat exchangers normalised capacity $\dot{\mathrm{Q}}_{\mathrm{HX} 1}, \dot{\mathrm{Q}}_{\mathrm{HX} 2}$ and $\dot{\mathrm{Q}}_{\mathrm{RHX}}(\mathrm{d})$.

a)

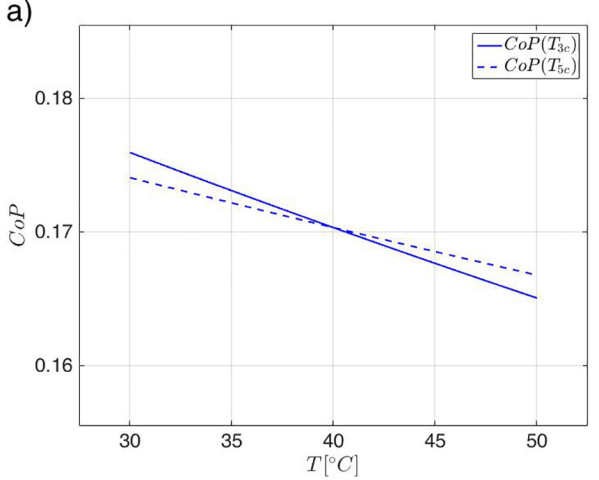

c)

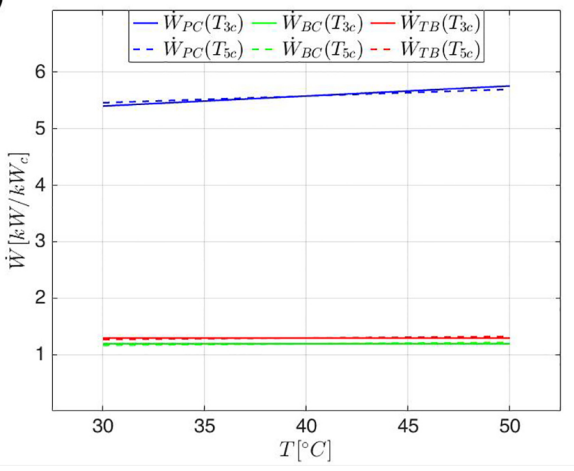

b)

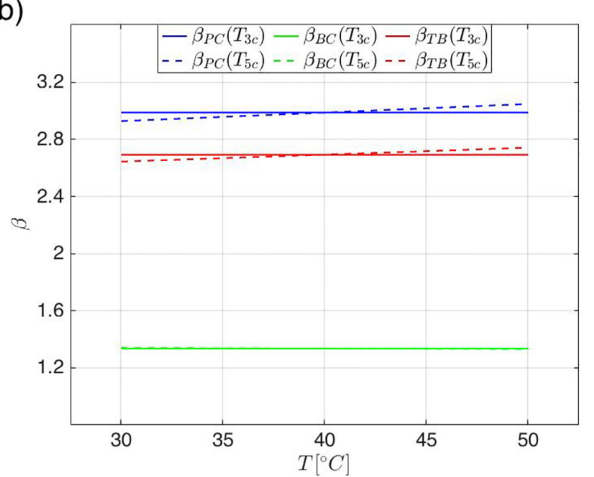

d)

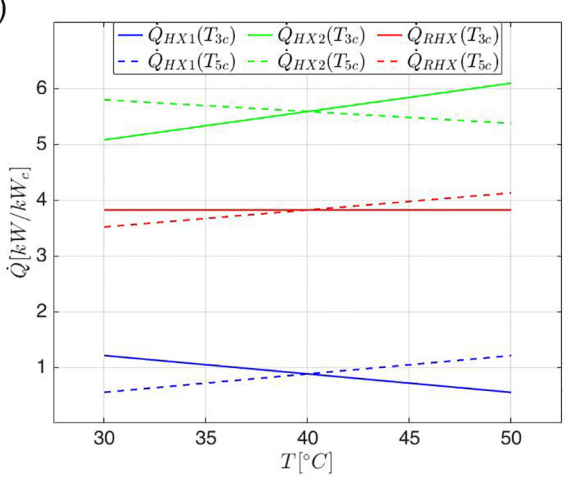

Fig. 5. Effect of the working fluid's temperature at HX1 and HX2 outlets on the modified rB cycle CoP (a), turbo-machineries pressure ratios $\beta_{\mathrm{PC}}, \beta_{\mathrm{BC}}$ and $\beta_{\mathrm{TB}}(\mathrm{b})$, normalised power $\dot{\mathrm{W}}_{\mathrm{PC}}, \dot{\mathrm{W}}_{\mathrm{BC}}$ and $\dot{\mathrm{W}}_{\mathrm{TB}}$ (c) and, finally, on the heat exchangers normalised capacity $\dot{\mathrm{Q}}_{\mathrm{HX} 1}, \dot{\mathrm{Q}}_{\mathrm{HX} 2}$ and $\dot{\mathrm{Q}}_{\mathrm{RHX}}(\mathrm{d})$. 
a)

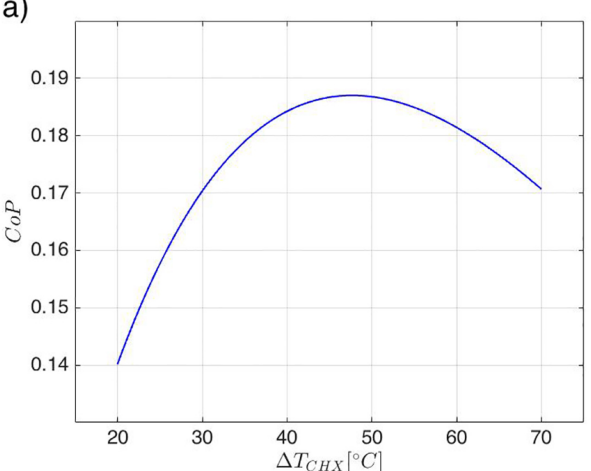

c)

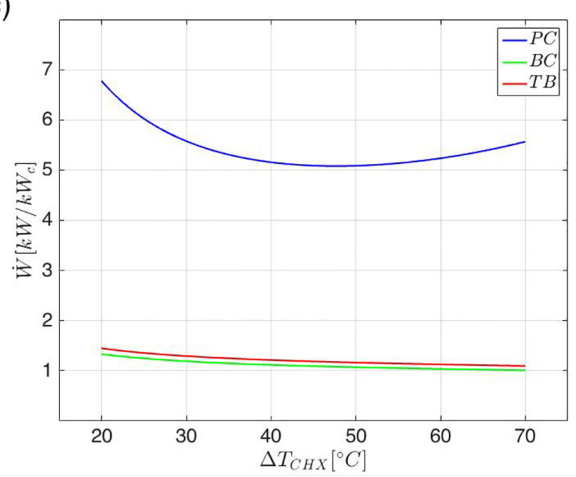

b)

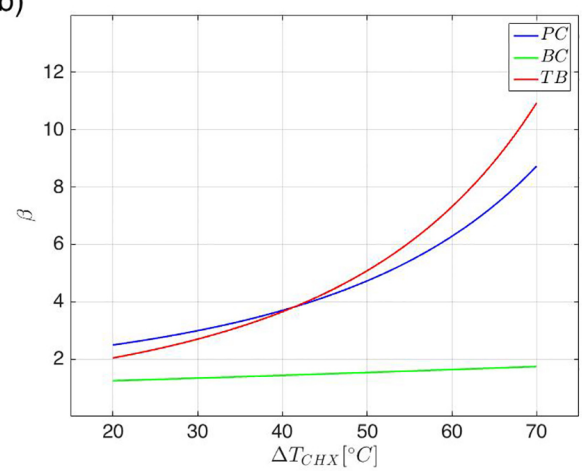

d)

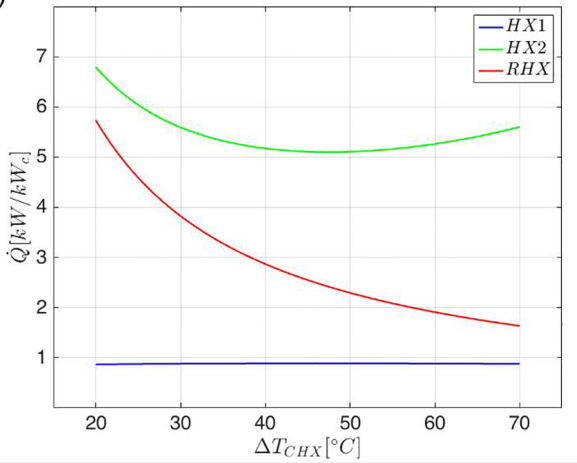

Fig. 6. Effect of the working fluid's temperature gap in CHX on the modified rB cycle CoP (a), turbo machines pressure ratios $\beta_{\mathrm{PC}}, \beta_{\mathrm{BC}}$ and $\beta_{\mathrm{TB}}(\mathrm{b})$, normalised power $\dot{\mathrm{W}}_{\mathrm{PC}}, \dot{\mathrm{W}}_{\mathrm{BC}}$ and $\dot{\mathrm{W}}_{\mathrm{TB}}$ (c) and, finally, on the heat exchangers normalised capacity $\dot{\mathrm{Q}}_{\mathrm{HX} 1}, \dot{\mathrm{Q}}_{\mathrm{HX} 2}$ and $\dot{\mathrm{Q}}_{\mathrm{RHX}}(\mathrm{d})$.

a)

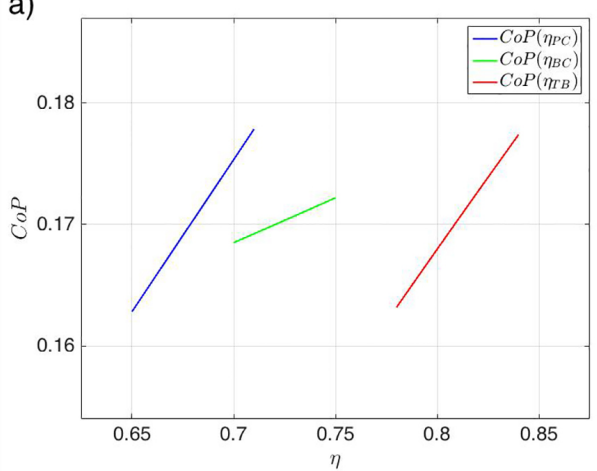

c)

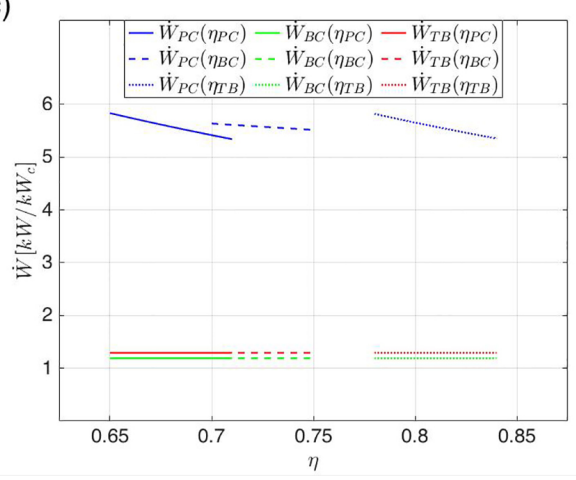

b)

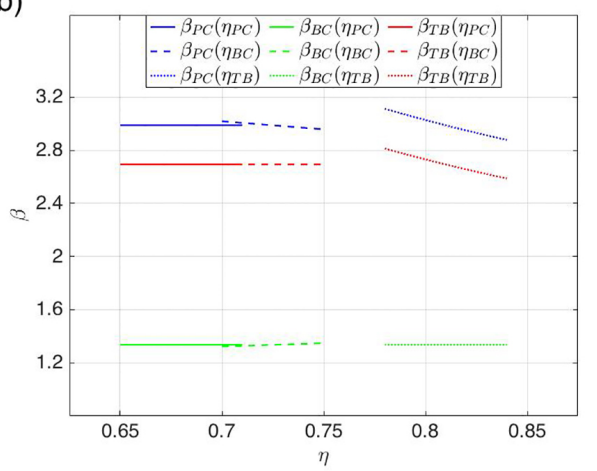

d)

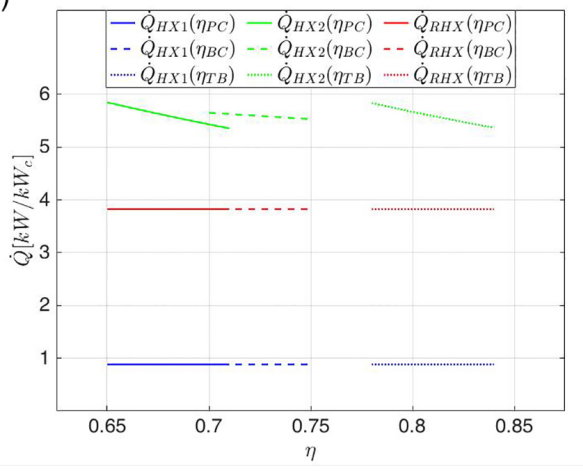

Fig. 7. Effect of the turbo-machineries' isentropic efficiency on the modified rB cycle CoP (a), turbomachineries pressure ratios $\beta_{\mathrm{PC}}, \beta_{\mathrm{BC}}$ and $\beta_{\mathrm{TB}}(\mathrm{b})$, normalised power $\dot{\mathrm{W}}_{\mathrm{PC}}, \dot{\mathrm{W}}_{\mathrm{BC}}$ and $\dot{\mathrm{W}}_{\mathrm{TB}}$ (c) and, finally, on the heat exchangers normalised capacity $\dot{\mathrm{Q}}_{\mathrm{HX} 1}, \dot{\mathrm{Q}}_{\mathrm{HX} 2}$ and $\dot{\mathrm{Q}}_{\mathrm{RHX}}(\mathrm{d})$. 


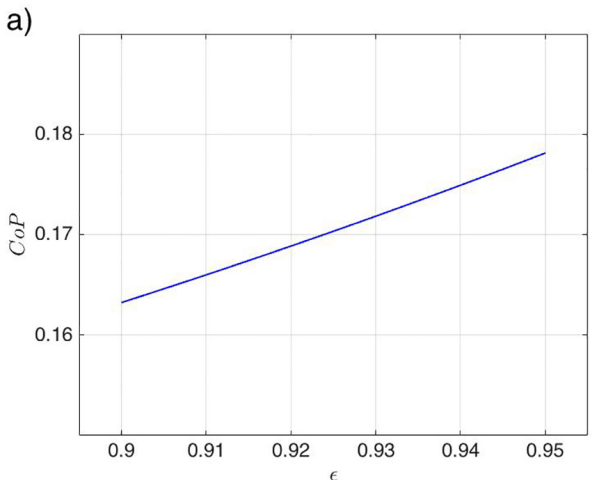

c)

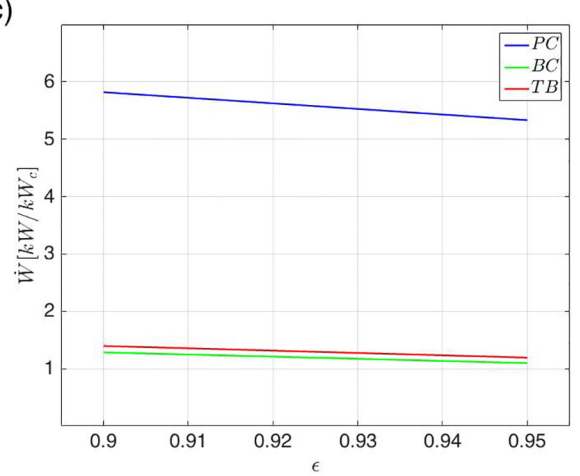

b)

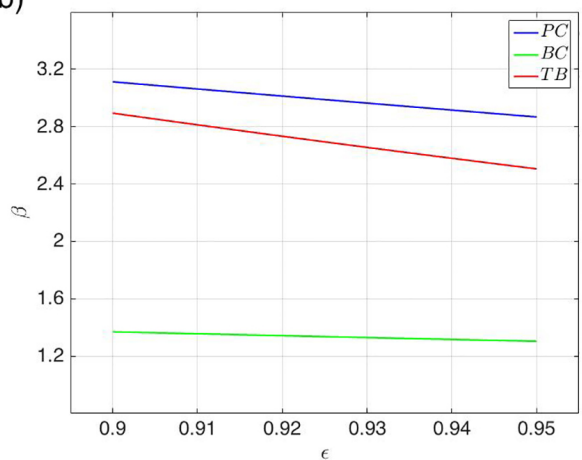

d)

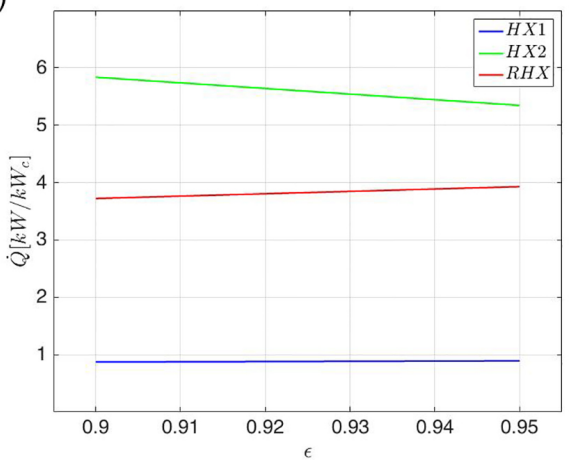

Fig. 8. Effect of the regenerator's effectiveness on the modified $\mathrm{rB}$ cycle $\mathrm{CoP}$ (a), turbo-machineries pressure ratios $\beta_{\mathrm{PC}}, \beta_{\mathrm{BC}}$ and $\beta_{\mathrm{TB}}(\mathrm{b})$, normalised power $\dot{\mathrm{W}}_{\mathrm{PC}}, \dot{\mathrm{W}}_{\mathrm{BC}}$ and $\dot{\mathrm{W}}_{\mathrm{TB}}$ (c) and, finally, on the heat exchangers normalised capacity $\dot{\mathrm{Q}}_{\mathrm{HX} 1}, \dot{\mathrm{Q}}_{\mathrm{HX} 2}$ and $\dot{\mathrm{Q}}_{\mathrm{RHX}}(\mathrm{d})$.

\section{Tables}

Table 1. Balance equations of the modified rB cycle components.

\begin{tabular}{l|l}
\hline Bootstrap compressor BC & $\dot{W}_{\mathrm{BC}}=\dot{m}_{\mathrm{N}}\left(h_{1 \mathrm{c}}-h_{2 \mathrm{c}}\right)$ \\
Heat exchanger HX1 & $Q_{\mathrm{HX} 1}=\dot{m}_{\mathrm{N}}\left(h_{2 \mathrm{c}}-h_{3 \mathrm{c}}\right)$ \\
Primary compressor PC & $\dot{W}_{\mathrm{PC}}=\dot{m}_{\mathrm{N}}\left(h_{3 \mathrm{c}}-h_{4 \mathrm{c}}\right)$ \\
Heat exchanger HX2 & $Q_{\mathrm{HX} 2}=\dot{m}_{\mathrm{N}}\left(h_{4 \mathrm{c}}-h_{5 \mathrm{c}}\right)$ \\
Regenerator RHX & $Q_{\mathrm{RHX}}=\dot{m}_{\mathrm{N}}\left(h_{5 \mathrm{c}}-h_{6 \mathrm{c}}\right)=\dot{m}_{\mathrm{N}}\left|\left(h_{8 \mathrm{c}}-h_{1 \mathrm{c}}\right)\right|$ \\
Turbine TB & $\dot{W}_{\mathrm{TB}}=\dot{m}_{\mathrm{N}}\left(h_{6 \mathrm{c}}-h_{7 \mathrm{c}}\right)$ \\
Heat exchanger CHX & $Q_{\mathrm{CL}}=\dot{m}_{\mathrm{N}}\left(h_{7 \mathrm{c}}-h_{8 \mathrm{c}}\right)$ \\
\hline
\end{tabular}


Table 2 - Reference parameters of the modified $\mathrm{rB}$ cycle performance analysis.

\begin{tabular}{ll|l}
\hline \multicolumn{2}{l|}{ Variable } & Value \\
\hline$p_{1 \mathrm{c}}$ & {$[\mathrm{kPa}]$} & 100 \\
$\Delta p_{\mathrm{HX} 1}$ & {$[\mathrm{kPa}]$} & 8 \\
$\Delta p_{\mathrm{HX} 2}$ & {$[\mathrm{kPa}]$} & 11 \\
$\Delta p_{\mathrm{RHX}}$ & {$[\mathrm{kPa}]$} & 14 (each side) \\
$\Delta p_{\mathrm{CHX}}$ & {$[\mathrm{kPa}]$} & 16 \\
$T_{3 \mathrm{c}}$ & {$\left[{ }^{\circ} \mathrm{C}\right]$} & 40 \\
$T_{5 \mathrm{c}}$ & {$\left[{ }^{\circ} \mathrm{C}\right]$} & 40 \\
$T_{8 \mathrm{c}}$ & {$\left[{ }^{\circ} \mathrm{C}\right]$} & -85 \\
$\Delta T_{\mathrm{CHX}}$ & {$\left[{ }^{\circ} \mathrm{C}\right]$} & 30 \\
$\varepsilon_{\mathrm{RHX}}$ & - & 0.925 \\
$\eta_{\mathrm{BC}}$ & - & 0.725 \\
$\eta_{\mathrm{TB}}$ & - & 0.810 \\
$f_{\mathrm{BU}}$ & - & 0.920 \\
$\eta_{\mathrm{PC}}$ & - & 0.680 \\
$\zeta_{\mathrm{M}}$ & - & 0.950 \\
\hline
\end{tabular}

Table 3 - Optimisation variables constraints and parameters values.

\begin{tabular}{cllll}
\hline Variables & \multicolumn{5}{c}{ Initial value } \\
\hline$p_{1 \mathrm{c}}$ & {$[\mathrm{kPa}]$} & 100 & 1000 & 550 \\
$\Delta T_{\mathrm{CHX}}$ & {$\left[{ }^{\circ} \mathrm{C}\right]$} & 20 & 50 & 35 \\
$\eta_{\mathrm{BC}}$ & {$[-]$} & 0.70 & 0.75 & 0.725 \\
$\eta_{\mathrm{PC}}$ & {$[-]$} & 0.65 & 0.71 & 0.68 \\
$\eta_{\mathrm{TB}}$ & {$[-]$} & 0.78 & 0.84 & 0.81 \\
$\varepsilon_{\mathrm{RHX}}$ & {$[-]$} & 0.90 & 0.95 & 0.925 \\
\hline Constant parameters & & & \\
\hline$\Delta p_{\mathrm{HX} 1}$ & {$[\mathrm{kPa}]$} & 8 & & \\
$\Delta p_{\mathrm{HX} 2}$ & {$[\mathrm{kPa}]$} & 11 & & \\
$\Delta p_{\mathrm{RHX}}$ & {$[\mathrm{kPa}]$} & $14($ each side) & & \\
$\Delta p_{\mathrm{CHX}}$ & {$[\mathrm{kPa}]$} & 16 & & \\
$T_{3 \mathrm{c}}$ & {$\left[{ }^{\circ} \mathrm{C}\right]$} & 40 & & \\
$T_{5 \mathrm{c}}$ & {$\left[{ }^{\circ} \mathrm{C}\right]$} & 40 & & \\
$T_{8 \mathrm{c}}$ & {$\left[{ }^{\circ} \mathrm{C}\right]$} & -85 & & \\
$f_{\mathrm{BU}}$ & {$[-]$} & 0.92 & & \\
$\zeta_{\mathrm{M}}$ & {$[-]$} & 0.95 & & \\
\hline
\end{tabular}


Table 4-Specifications of the optimised modified rB cycle.

\begin{tabular}{|c|c|c|c|}
\hline \multicolumn{4}{|c|}{ Thermodynamic parameters } \\
\hline \multicolumn{2}{|c|}{ Temperature $\left[{ }^{\circ} \mathrm{C}\right]$} & \multicolumn{2}{|c|}{ Pressure $[\mathrm{kPa}]$} \\
\hline$T_{1 \mathrm{c}}$ & 33.7 & $p_{1 \mathrm{c}}$ & 1000 \\
\hline$T_{2 \mathrm{c}}$ & 65.6 & $p_{2 \mathrm{c}}$ & 1300 \\
\hline$T_{3 \mathrm{c}}$ & 40.0 & $p_{3 \mathrm{c}}$ & 1292 \\
\hline$T_{4 \mathrm{c}}$ & 131.2 & $p_{4 \mathrm{c}}$ & 2494 \\
\hline$T_{5 \mathrm{c}}$ & 40.0 & $p_{5 c}$ & 2483 \\
\hline$T_{6 \mathrm{c}}$ & -74.7 & $p_{6 c}$ & 2469 \\
\hline$T_{7 \mathrm{c}}$ & -113.9 & $p_{7 \mathrm{c}}$ & 1030 \\
\hline$T_{8 \mathrm{c}}$ & -85.0 & $p_{8 \mathrm{c}}$ & 1014 \\
\hline \multicolumn{4}{|c|}{ Turbo machineries specification $\left[\mathrm{kW} \cdot \mathrm{kW}_{\mathrm{c}}^{-1}\right]$} \\
\hline$W_{\mathrm{BC}}$ & \multicolumn{3}{|c|}{1.03} \\
\hline$\dot{W}_{\mathrm{PC}}$ & \multicolumn{3}{|l|}{2.95} \\
\hline$\dot{W}_{\mathrm{TB}}$ & \multicolumn{3}{|l|}{1.12} \\
\hline \multicolumn{4}{|c|}{ Heat exchangers specification $\left[\mathrm{kW} \cdot \mathrm{kW}_{\mathrm{c}}^{-1}\right]$} \\
\hline$\overline{Q_{\mathrm{HX} 1}}$ & \multicolumn{3}{|l|}{0.84} \\
\hline$Q_{\mathrm{HX} 2}$ & \multicolumn{3}{|l|}{3.02} \\
\hline$Q_{\mathrm{RHX}}$ & \multicolumn{3}{|l|}{3.94} \\
\hline \multicolumn{4}{|c|}{ Nitrogen mass flow rate $\left[\mathrm{kg} \cdot \mathrm{s}^{-1} \cdot \mathrm{kW}_{\mathrm{c}}^{-1}\right]$} \\
\hline$\dot{m}_{\mathrm{N}}$ & \multicolumn{3}{|l|}{0.031} \\
\hline \multicolumn{4}{|c|}{ rB-modified cycle performance } \\
\hline CoP & 0.322 & & \\
\hline
\end{tabular}

\section{Nomenclature}

Plant component

BC bootstrap compressor

BU bootstrap unit

CHX cold heat exchanger

HX1 first heat exchanger

HX2 second heat exchanger

M electric motor

PC primary compressor

RHX regenerative heat exchanger

TB turbine

Component ' $x$ ' parameters

$\begin{array}{lll}\mathrm{l}_{\mathrm{x}} & \text { work per mass unit } & \mathrm{J} \mathrm{kg}^{-1} \\ \mathrm{q}_{\mathrm{x}} & \text { heat per mass unit } & \mathrm{J} \mathrm{kg}^{-1} \\ \dot{\mathrm{Q}}_{\mathrm{x}} & \text { thermal capacity } & \mathrm{W} \\ \dot{\mathrm{W}}_{\mathrm{x}} & \text { mechanical power } & \mathrm{W} \\ \beta_{\mathrm{x}} & \text { pressure ratio } & \\ \Delta \mathrm{p}_{\mathrm{x}} & \text { pressure drop } & \mathrm{Pa}\end{array}$




$$
\begin{array}{ll}
\varepsilon_{\mathrm{x}} & \text { heat exchanger effectiveness } \\
\zeta_{\mathrm{x}} & \text { electric efficiency } \\
\eta_{\mathrm{x}} & \text { isentropic efficiency }
\end{array}
$$

Other symbols

$\begin{array}{lll}\mathrm{f}_{\mathrm{BU}} & \text { bootstrap unit mechanical losses } & \\ \dot{\mathrm{m}}_{\mathrm{N}} & \text { nitrogen mass flow rate } & \mathrm{kg} \mathrm{s}^{-1} \\ \mathrm{p}_{\mathrm{i}} & \text { pressure at } \mathrm{i} \text {-th thermodynamic state } & \mathrm{Pa} \\ \mathrm{T}_{\mathrm{i}} & \text { temperature at } \mathrm{i} \text {-th thermodynamic state } & { }^{\circ} \mathrm{C} \\ \mathrm{CoP} & \text { coefficient of performance } & \end{array}$

\section{Acknowledgements}

This research was partially funded by projects "SACS" (POR FESR 2007-2013, Polo Innovazione Agroalimentare) and "CRYOFOOD" (POR FESR 2014-2020, Polo Innovazione AgriFood). The authors wish to thank Criotec Impianti S.r.I., Dyria Sistemi S.r.I. and ZOPPI S.r.I. project partners for their active collaboration.

\section{References}

Ahmadi, M. H., Ahmadi M. A., Mohammadi A. H., Feidt M., Pourkiaei S. M., 2014. Multi-objective optimization of performance of an irreversible Stirling cryogenic refrigerator cycle. Energ Convers Manage 82, 351-360.

Ahmadi, M. H., Ahmadi M. A., 2016. Multi objective optimization of performance of three-heat-source irreversible refrigerators based algorithm NSGAII. Renew Sust Energ Rev 60, 784-794.

Ahmadi, M. H., Ahmadi M. A., Pourfayaz F., Bidi M., 2016. Thermodynamic analysis and optimization for an irreversible heat pump working on reversed Brayton cycle. Energ Convers Manage 110, 260-267.

ASHRAE, 2010. Refrigeration ASHRAE Handbook. ISBN 9781933742823.

Ashrafi, O., Bédard, S., Bakhtiari, B., Poulin, B., 2015. Heat recovery and heat pumping opportunities in a slaughterhouse. Energy 89, 1-13.

Awonorin, A.O., 1997. An Appraisal of the Freezing Capabilities of Tunnel and Spiral Belt Freezers Using Liquid Nitrogen Sprays. J Food Eng 34, 179-192.

$\mathrm{Bi}, \mathrm{Y}$. , Chen L., Sun F., 2008. Heating load density and COP optimizations for an endoreversible air heat pump. Appl Energ 85, 607-617.

Bi, Y., Chen L., Sun F., 2009. Comparative performance analysis for endoreversible simple air heat pump cycles considering ecological, exergetic efficiency and heating load objectives. Int J Exergy 6, 550-566.

Bi, Y., Xie G., Chen L., Sun F., 2012. Heating load density optimization of an irreversible simple Brayton cycle heat pump coupled to counter-flow heat exchangers. Appl Math Model 36, 1854-1863.

Biglia, A., Fabrizio, E., Ferrara, M., Gay, P., Ricauda Aimonino, D., 2015. Performance assessment of a multienergy system for a food industry. Energy Procedia 82, 540-545.

Biglia, A., Comba, L., Fabrizio, E., Gay, P., Ricauda Aimonino, D., 2016. Case studies in food freezing at very low temperature. Energy Procedia 101, 305-312. 
Biglia, A., Comba, L., Fabrizio, E., Gay, P., Ricauda Aimonino, D., 2017. Steam batch thermal processes in unsteady state conditions: Modelling and application to a case study in the food industry. Appl Therm Eng $118,638-651$.

Castro-Giráldez, M., Balaguer, B., Hinarejos, E., Fito, P.J., 2014. Thermodynamic approach of meat freezing process. Innov Food Sci Emerg 23, 138-145.

Chang, H.-M., Chung, M.J., Kim, M.J., Park, S.B., 2009. Thermodynamic design of methane liquefaction system based on reversed-Brayton cycle. Cryogenics 49, 226-234.

Comba, L., Gay, P., Piccarolo, P., Ricauda Aimonino, D., 2010. Thermal processes in the candy process of chestnut. Acta Horticulturae 866, 587-594.

Comba, L., Belforte, G., Gay, P., 2011. Modelling techniques for the control of thermal exchanges in mixed continuous-discontinuous flow food plants. J Food Eng 106, 177-187.

Dempsey, P., Bansal, P., 2012. The art of air blast freezing: Design and efficiency considerations. Appl Therm Eng 41, 71-83.

Di Matteo, P., Donsì, G., Ferrari, G., 2003. The role of heat and mass transfer phenomena in atmospheric freeze-drying of foods in a fluidised bed. J Food Eng 59, 267-275.

Dopazo, J.A., Fernández-Seara, J., 2012. Experimental evaluation of freezing processes in horizontal plate freezers using CO2 as refrigerant. Int J Refrig 35, 2093-2101.

Foster, A.M., Brown, T., Gigiel, A.J., Alford, A., Evans, J.A., 2011. Air cycle combined heating and cooling for the food industry. Int J Refrig 34, 1296-1304.

Elsayed, E.S., Akisawa, A., Kashiwagi, T., Hamamoto, Y., 2006. Using air cycle refrigerator integrated desiccant system for simultaneous usage in supermarket: refrigerating and ventilated air conditioning. Proc. of the 3rd Asian Conference on Refrigeration and Air-Conditioning vols. I and II (ACRA2006). May 21-23 Gyeongju, Korea.

Galetto, C.D., Verdini, R.A., Zorrilla, S.E., Rubiolo, A.C., 2010. Freezing of strawberries by immersion in $\mathrm{CaCl} 2$ solutions. Food Chem 123, 243-248.

Gazda, W., 2013. Application possibilities of the strategies of the air blast-cryogenic cooling process. Energy 62, 113-119.

Giannetti, M., Milazzo, A., 2014. Thermodynamic analysis of regenerated air-cycle refrigeration in high and low pressure configuration. Int J Refrig 40, 97-110.

Hou, S., Li, H., Zhang, H., 2008. An open air-vapor compression refrigeration system for air-conditioning and desalination on ship. Desalination 222, 646-655.

Hou, S., Zhang, H., 2009. An open reversed Brayton cycle with regeneration using moist air for deep freeze cooled by circulating water. Int J Therm Sci 48, 218-223.

Huan, Z., He, S., Ma, Y., 2003. Numerical simulation and analysis for quick-frozen food processing. J Food Eng 60, 267-273.

Islam, Md.N., Zhang, M., Adhikari, B., Xinfeng, C., Xu, B., 2014. The effect of ultrasound-assisted immersion freezing on selected physicochemical properties of mushrooms. Int J Refrig 42, 121-133.

James, S.J., James, C., 2002. Meat Refrigeration, Woodhead Publishing in food and science and technology. ISBN 1855734427.

Kaale, L.D., Eikevik, T.M., Rustad, T., Kolsaker, K., 2011. Superchilling of food: A review. J Food Eng 107, 141146 
Kim, Y.H.B., Liesse, C., Kemp, R., Balan, P., 2015. Evaluation of combined effects of ageing period and freezing rate on quality attributes of beef loins. Meat Sci 110, 40-45.

Ledesma, E., Laca, A., Rendueles, M., Díaz, M., 2016. Texture, colour and optical characteristics of a meat product depending on smoking time and casing type. LWT-Food Sci Technol 65, 164-172.

Lerfall, J., Bendiksen, E.A., Olsen, J.V., Østerlie, M., 2016. A comparative study of organic-versus conventional Atlantic salmon. II. Fillet color, carotenoid- and fatty acid composition as affected by dry salting, cold smoking and storage. Aquaculture 451, 369-376.

Li, X., Babol, J., Bredie, W.L.P., Nielsen, B., Tománková, J., Lundström, K., 2014. A comparative study of beef quality after ageing longissimus muscle using a dry ageing bag, traditional dry ageing or vacuum package ageing. Meat Sci 97, 433-442.

Li, S., Wang, S., Ma, Z., Jiang, S., Zhang, T., 2017. Using an air cycle heat pump system with a turbocharger to supply heating for full electric vehicles. Int J Refrig 77, 11-19.

Llopis, R., Sánchez, D., Sanz-Kock, C., Cabello, R., Torrella, E., 2015. Energy and environmental comparison of two-stage solutions for commercial refrigeration at low temperatures: Fluids and systems. Appl Energ $138,133-142$.

Moran, M.J., Shapiro, H.N., 2006. Fundamentals of Engineering Thermodynamics. Fifth ed., John Wiley \& Sons.

NIST Reference Fluid Thermodynamic and Transport Properties Database: Version 9.1. National Institute of Standards and Technology (Standard Reference Data). United States Department of Commerce. Gaithersburg, Maryland.

Perussello, C.A., Mariani, V.C., do Amarante, Á.C., 2011. Combined modelling of thermal properties and freezing process by convection applied to green beans. Appl Therm Eng 31, 2894-2901.

Reynoso, R.O., Calvelo, A., 1985. Comparison between fixed and fluidized bed continuous pea freezers. Int J Refrig 8, 109-115.

Rogers, B.H., 1994. Cooling in aircraft. Proceedings of the Institute of Refrigeration 91, 4-11.

Salvadori, V.O., Mascheroni, R.H., 2002. Analysis of impingement freezers performance. J Food Eng 54, 133140.

Shaikh, N.I., Prabhu, V., 2007. Mathematical modelling and simulation of cryogenic tunnel freezers. J Food Eng 80, 701-710.

Spence, S.W.T., Doran, W.J., Artt, D.W., 2004. Design, construction and testing of an air-cycle refrigeration system for road transport. Int J Refrig 27, 503-510.

Spence, S.W.T., Doran, W.J., Artt, D.W., McCullough, G., 2005. Performance analysis of a feasible air-cycle refrigeration system for road transport. Int J Refrig 28, 381-388.

Soyer, A., Özalp, B., Dalmiş, Ü., Bilgin V., 2010. Effects of freezing temperature and duration of frozen storage on lipid and protein oxidation in chicken meat. Food Chem 120, 1025-1030.

Streit, J., Razani, A., 2013. Thermodynamic optimization of reverse Brayton cycles of different configurations for cryogenic applications. Int J Refrig 36, 1529-1544.

Tian, Y., Zhao, Y., Huang, J., Zeng, H., Zheng, B., 2016. Effects of different drying methods on the product quality and volatile compounds of whole shiitake mushrooms. Food Chem 197, 714-722.

Xin, Y., Zhang, M., Xu, B., Adhikari, B., Sun, J., 2015. Research trends in selected blanching pretreatments and quick freezing technologies as applied in fruits and vegetables: A review. Int J Refrig 57, 11-25. 
Xu, B., Zhang, M., Bhandari, B., Sun, J., Gao, Z., 2016. Infusion of CO2 in a solid food: A novel method to enhance the low-frequency ultrasound effect on immersion freezing process. Innov Food Sci Emerg 35, 194203. 